\title{
ATUAÇÃO DE UMA EQUIPE MULTIPROFISSIONAL EM TEMPOS DE CORONAVÍRUS
}

\author{
PERFORMANCE OF A MULTIPROFESSIONAL TEAM IN TIMES OF \\ CORONAVIRUS
}

\author{
André Luiz Dantas Bezerra ${ }^{1}$ \\ Emana Jéssica Ferreira Rodrigues \\ Lúcia Helena Gomes Gouveia Souto \\ Alexia Ruanna Oliveira da Nóbrega \\ Nelmara Sousa Silva \\ Milena Nunes Alves de Sousa
}

\begin{abstract}
RESUMO: Objetivo: Relatar a experiência de uma equipe multiprofissional de residentes em Atenção Primária à Saúde (APS) na prestação de cuidados à população durante o período de pandêmico da COVID-19. Métodos: Trata-se de um relato de experiência, descritivo-qualitativo, vivenciado em tempo de pandemia na Unidade Básica de Saúde âncora em COVID-19, Metódio Araújo Leitão, Zona Sul do município de Patos, Paraíba. O relato envolveu a descrição das ações realizadas entre os meses de março a junho de 2020 pelos residentes multiprofissionais em Atenção Primária à Saúde e Saúde Comunitária do Centro Universitário de Patos (UNIFIP). Relato de experiência: As atividades desenvolvidas englobaram ações multiprofissionais referentes ao enfrentamento para o combate a COVID-19, em que foram reorganizados os ambientes de saúde, feito acolhimento, com triagem, consulta médica, notificação dos casos suspeitos e monitoramento, bem como ações de educação em saúde e teletrabalho. Conclusão: Com as ações desenvolvidas em equipe na APS, foi possível verificar a importância do trabalho colaborativo, o que possibilitou a efetivação de protocolos e fluxogramas, readequação da estrutura física para oportuno acolhimento de casos suspeitos e confirmados, o monitoramento quase diário pelo teletrabalho, bem como de ações educativas, garantindo o acesso à saúde, bem como uma assistência de qualidade, integral, longitudinal e resolutiva.
\end{abstract}

Palavras chave: Pandemia, Atenção Primária à Saúde, Educação em Saúde, Telemedicina.

Residência Multiprofissional em Atenção Primária à Saúde. Centro Universitário de Patos (UNIFIP), Patos, Paraíba. E-mail: dr.andreldb@gmail.com. 
ABSTRACT: Objective: To report the experience of a multidisciplinary team of residents in Primary Health Care (PHC) in the provision of care to the population during the pandemic period of coronavirus (COVID-19), Methods: This is a descriptive-qualitative experience report experienced in pandemic time at the anchor Basic Health Unit in COVID-19, Metódio Araújo Leitão, South Zone of Patos, Paraiba. The report involved the description of the actions carried out between March and June 2020 by multidisciplinary residents in Primary Health care and Community Health of the University Center of Patos (UNIFIP). Experience report: The activities developed included multidisciplinary actions related to coping to combat COVID-19, in which health environments were reorganized, with medical consultation screening, notification of suspected cases and monitoring, as well as health education and telework actions. Conclusion: With the actions developed as na PHC team, it was possible to verify the importance of collaborative work, which allowed the implementation of protocols and flowcharts, readjustment of the physical structure for timely reception of suspected and confirmed cases, almost daily monitoring by telework, as well as educational actions, ensuring access to health, as well as quality, comprehensive, longitudinal and problem-solving care.

Keywords: Pandemic, Primary Health Care, Health Education, Telemedicine. 


\section{INTRODUÇÃO}

Em dezembro de 2019 na cidade de Wuhan, província de Hubei - China foram identificados os primeiros casos de pacientes infectados pelo novo vírus corona (COVID-19), se transformando tão logo em uma pandemia, espalhando-se rapidamente para outros vinte e quatro países (CRUZ et al., 2020; TUÑAS et al., 2020).

De acordo com o Centers for Disease Control and Prevention (CDC, 2020), agência americana vinculada ao Departamento de Saúde e Serviços Humanos, foi batizado como Severe Acute Respiratory Syndrome Coronavirus 2 (SARS-CoV-2), causador da doença COVID-19. Sua estrutura assemelha-se a uma coroa, possuindo uma fita de ácido ribonucléico (RNA) helicoidal e envelopada, podendo causar sintomas bem variados, desde um resfriado leve (80\% dos casos) a Síndrome Respiratória Aguda Grave (SARS) (5\% e 10\% dos sintomáticos). A gravidade da sintomatologia está associada com a presença de comorbidades préexistentes.

Apesar de a maioria dos casos se apresentar assintomática ou com sintomas leves, o vírus da COVID-19 é altamente contagioso e pode ser transmitido pelo contato de pessoa-pessoa, assim como por gotículas espalhadas pela tosse ou espirros de um indivíduo infectado (FILGUEIRAS; STULTS-KOLEHMAINEN, 2020; ROTHAN; BYRAREDDY, 2020). Conforme os autores, independente de a pessoa estar sintomática ou assintomática, a transmissão ainda é possível.

É oportuno ressaltar que os primeiros sintomas da COVID-19 poderão se manifestar entre cinco e seis dias (ROTHAN; BYRAREDDY, 2020). Esse espaço temporal é denominado de incubação, em que é possível surgir sintomas leves como presença de febre, tosse e fadiga.

Ainda os autores Rothan e Byrareddy (2020) relatam que a sintomatologia de maior gravidade inclui produção de escarro, cefaléia, hemoptise, diarréia, dispnéia e linfopenia, podendo levar à morte em um espaço de tempo que varia de 6 a 41 dias, 
exacerbação média em até 14 dias, resposta imunodependente e variável conforme a faixa etária do paciente, em que os idosos são os mais afetados.

Em decorrência desta pandemia, portanto, a saúde pública tem sofrido com grandes impactos, especialmente pela facilidade de proliferação na população induzindo, assim, a ocorrência de alterações abruptas para o enfrentamento a SARS-CoV-2 em todo o território nacional (GALLASCH et al., 2020) e, especialmente, na Atenção Primária à Saúde (APS).

No Brasil, a APS apresenta grande relevância para o enfrentamento positivo da doença, mediante ações objetivando a prevenção e controle do agravo, como o engajamento das Equipes Saúde da Família (ESF) que estão promovendo educação em saúde e acolhendo demandas de usuários sintomáticos ou assintomáticos (CRUZ et al., 2020; MINISTÉRIO DA SAÚDE - MS, 2020).

Enquanto primeiro nível de atenção, as ESF têm atuado como âncora para acolher aqueles usuários que apresentam os primeiros sinais e sintomas do COVID19 ou com sintomas leves. Assim, tem garantido a coordenação do cuidado, em prol da redução significativa de encaminhamentos que seriam realizados desnecessariamente para os hospitais e pronto atendimento (CRUZ et al., 2020; HARZHEIM et al., 2020).

Cada membro da equipe multiprofissional tem papel e atribuições relevantes diante de um suspeito de Síndrome Gripal (SG), bem como devem estar capacitados à realização dos atendimentos de uma forma segura, com utilização de equipamento de proteção individual (EPI) (MS, 2020).

Diante desta nova realidade, o artigo objetiva relatar a experiência de uma equipe multiprofissional de residentes em Atenção Primária à Saúde na prestação de cuidados à população durante o período de pandêmico da COVID-19.

\section{MATERIAL E MÉTODO}

Trata-se de um relato de experiência, descritivo-qualitativo, vivenciado em tempo de pandemia na Unidade Básica de Saúde (UBS), Metódio Araújo Leitão, 
bairro Monte Castelo, Zona Sul do município de Patos, Paraíba (PB), Distrito GeoAdministrativo IV (DGA-IV). Ressalta-se que o município é mapeado por DGAs, o que auxilia na facilitação do trabalho em saúde e permite a criação dos Conselhos Distritais para atuar em cada uma das 41 UBS locais. O conselho distrital tem o papel de ser consultivo sobre as ações e serviços de saúde, apoiando-se na integralidade e no apoio matricial.

No mais, Patos-PB está localizada no sertão do estado e tem, em média, uma população de 100.674 pessoas, com rendimentos por domicílios mensais de até meio salário mínimo por pessoa, ficando dentre os 223 municípios do Estado da Paraíba na posição 219 de 223 e na posição 2510 de 5570 dentre as cidades do Brasil (IBGE, 2010). No contexto da saúde, o município conta com 41 UBS, dividido em 04 zonas/DGA: Norte, Sul, Leste e Oeste; além de duas unidades de pronto atendimento (UPA) e quatro hospitais, destes três são públicos, com atendimento infantil, materno e geral (PREFEITURA MUNICIPAL DE PATOS, 2018).

A equipe da UBS é composta pela equipe mínima preconizada, composta por médico, cirurgião dentista, enfermeira, técnico em saúde bucal, auxiliar de limpeza, atendente e seis Agentes Comunitários de Saúde (ACS). Contudo, agora integram os estudantes da Residência Multiprofissional em Atenção Primária à Saúde e Saúde Comunitária do Centro Universitário de Patos (UNIFIP) em parceria com Prefeitura Municipal de Patos, ou seja, um cirurgião dentista, uma enfermeira e uma assistente social.

Assim sendo, o relato envolve a descrição das ações realizadas entre os meses de março a junho de 2020 pelos referidos estudantes multiprofissionais. A seguir, têm-se as atividades desenvolvidas com seus respectivos objetivos (Quadro 1). 
Quadro 1 - Atividades desenvolvidas na UBS Metódio Araújo Leitão e objetivos. Patos-PB, 2020.

\begin{tabular}{|l|l|}
\hline \multicolumn{1}{|c|}{ Atividades } & \multicolumn{1}{c|}{ Objetivos } \\
\hline Inclusão na UBS & Conhecer a equipe \\
\hline Referência âncora & Enfrentamento para o combate ao COVID-19 \\
\hline $\begin{array}{l}\text { Reorganização dos ambientes } \\
\text { de saúde }\end{array}$ & Preparar a UBS com fluxograma \\
\hline Acolhimento & $\begin{array}{l}\text { Triagem consulta médica, notificação dos casos } \\
\text { suspeitos e monitoramento }\end{array}$ \\
\hline Educação em Saúde & Informar e orientar os pacientes \\
\hline Teletrabalho & $\begin{array}{l}\text { Acompanhar a cada 48 horas a evolução do } \\
\text { usuário. }\end{array}$ \\
\hline
\end{tabular}

Fonte: Autoria Própria (2020).

Ressalta-se que pela natureza do trabalho, não houve necessidade de submissão a Comitê de Ética em pesquisa, portanto, sendo respeitadas as normas de pesquisas envolvendo seres humanos.

\section{RESULTADOS E DISCUSSÃO}

A nossa inclusão na UBS deu-se, no primeiro momento, para conhecer a estrutura física da UBS. Constatou-se que a mesma é bem estruturada, climatizada e possui recepção com uma sala de espera ventilada, banheiro social, almoxarifado, sala de curativos, de vacina, de reunião e pesagem, ambulatórios (médico e de enfermagem) com banheiro anexo, sala do cirurgião-dentista, cozinha, expurgo e banheiro para funcionários.

Portanto, a estrutura possibilita o trabalho em equipe da ESF. O Ministério da Saúde preconiza que a mesma seja formada pelos seguintes profissionais: agentes comunitários de saúde (ACS), equipe de enfermagem (enfermeiros, técnicos e/ou auxiliares de enfermagem), equipe odontológica (cirurgião-dentista, técnico ou auxiliar consultório dentário) e médicos (BRASIL, 2017). 
No mesmo dia houve uma reunião presidida pela enfermeira da UBS com todos os profissionais que fazem parte da equipe. O momento serviu para a apresentação, acolhimento e integração dos novos membros, posteriormente, os ACS e residentes dialogaram conceberam um levantamento de dados da área, possibilitando um diagnóstico situacional do território. Em síntese, com a interação ACS-Residentes, propôs-se qualificar o processo de trabalho, promover vigilância em saúde e contribuir com melhorias nos indicadores de saúde locais, bem como conhecer as principais dificuldades enfrentadas pelos ACS e traçar um plano de ação para enfrentamento e resolutividade das mesmas.

Sabe-se que o desempenho de ações de qualidade realizadas pelos profissionais da equipe está intimamente relacionado aos indicadores de saúde (VIEIRA et al., 2020). Ademais, conforme os autores, as ações de vigilância em saúde devem integrar práticas tanto coletivas quanto individuais englobando necessidades de saúde distintas, com olhares direcionados ao controle dos riscos, abordagem dos determinantes sociais em saúde, bem como o ato de planejar estratégias alinhadas com a realidade territorial.

Por conseguinte, em detrimento da pandemia, a continuidade da efetivação do planejamento de saúde foi interrompida momentaneamente, pois a gestão do município referenciou quatro UBS para realização da assistência à saúde aos pacientes suspeitos e confirmados do COVID-19, denominadas de unidades âncora. "No Brasil, a região Nordeste é a segunda região com maior número de casos confirmados de COVID-19" (MARINELLI et al., 2020, p. 3), o que indica a necessidade de uma atenção especial.

Os indicadores do COVID-19 no país, e na região nordeste, sinalizaram para a importância de intervenções no campo da atenção primária (SARTI et al., 2020) e, assim, evitar a superlotação da atenção terciária, que indicava insuficiência de leitos para atendimento aos mais graves e contenção da pandemia (MARINELLI et al., 2020).

Segundo Sarti et al. (2020) é fundamental, na APS, a reorganização dos ambientes de saúde, implementação de estratégias específica para o enfrentamento da pandemia do COVID-19. Os autores destacam a implantação de protocolos e fluxogramas, adequação da estrutura física para atendimento dos casos suspeitos e 
confirmados, quantidade satisfatória de profissionais de saúde e equipamentos de proteção individual para os profissionais e usuários sintomáticos.

Destarte, como medida, passamos a trabalhar na linha de frente. Para os atendimentos prestados na UBS âncora foi refeito o fluxo de acolhimento na unidade. Aos usuários com síndrome gripal (SG) suspeitos de COVID-19 contemplaram acolhimento, triagem, consulta médica, encaminhamentos, notificação dos casos suspeitos, monitoramento mediante tele-atendimento dos casos confirmados que estão em isolamento domiciliar e orientação sobre as medidas de prevenção do COVID-19, em conformidade com o protocolo do MS (2020), educação em saúde - carro de som, panfletagem (Figura 1), vídeos, além de outras estratégias.

Figura 1 - Carro de som com nota informativa e panfletagem nas ruas. Patos-PB, 2020.

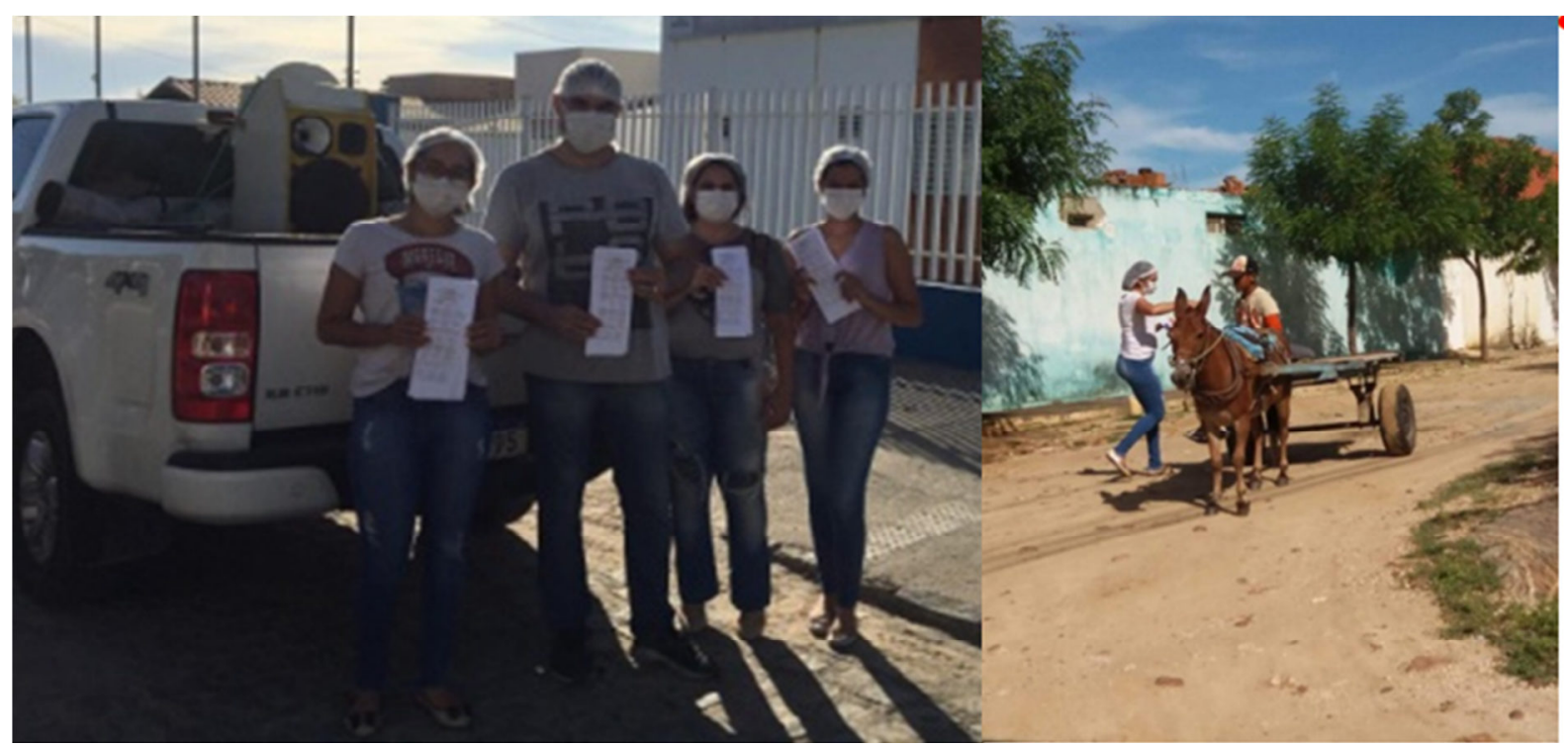

Fonte: Arquivo Pessoal (2020).

Quanto às informações a serem transmitidas, o MS (2020) recomenda repassar orientações sobre medidas de proteção para todos os usuários que procuram o serviço, como: lavar as mãos constantemente, manter desinfetado objetos e superfícies que foram tocados, distanciamento de no mínimo um metro entre pessoas, ao tossir e/ou espirrar, levar o cotovelo flexionado cobrindo a boca e 
nariz ou usar um lenço de papel, descartado após seu uso, não tocar a boca e/o nariz sem lavar as mãos antes, se estiver apresentando alguns sintomas de SG usar máscaras descartáveis, bem como o atendimento individualizado.

"Com isso, é de extrema relevância que as comunidades e instituições sociais incorporem práticas educativas voltadas à promoção da saúde [...], tendo em vista o impacto [...] sobre a saúde pública" (VERMELHO et al., 2014, p. 181). Para facilitar o acesso a tais conhecimentos e o autocuidado, foram criados vídeos ilustrativos (Figura 2), os quais foram disponibilizados no youtube, apresentados e validados por toda a equipe, o que possibilitou a interdisciplinaridade na construção de um recurso didático, "amparando-se em elementos lúdicos, levando os participantes a uma interação que permite a reconstrução do saber e do fazer em saúde" (PEREIRA et al., 2019, p. 77), bem como repassadas para os usuários a partir dos ACS, mediante rede social - WhatsApp.

Acredita-se que as redes sociais são excelentes tecnologias de comunicação, uma poderosa e eficiente ferramenta de circulação ágil e acessível de informação da atualidade. Para os autores "com um smartphone à mão, todo tipo de comunicação é quase instantânea, mensagens podem ser encaminhadas a qualquer momento, por/para qualquer pessoa (VERMELHO et al., 2014, p. 192). Fundamentais e relevantes dispositivos de apoio ao letramento (GASQUE, 2016) em saúde. Destacase que a alfabetização em saúde é essencial ao conhecimento e entendimento do usuário sobre as variáveis que influenciam sobre sua saúde, aqueles sujeitos com dificuldades de compreensão ou limitações de saberes em saúde têm piores escores de qualidade de vida e promoção de saúde (SOUSA et al., 2020).

Por conseguinte, para Camargo e Spinelli (2016), os vídeos publicizados nas redes sociais são uma alternativa estratégica para seduzir e engajar a audiência sobre um contexto específico, bem como fortalecer vínculos, fundamental entre equipe e os usuários de saúde. 
Figura 2 - Vídeos ilustrativos contendo orientações gerais sobre a COVID-19 e medidas de prevenção. Patos-PB, 2020.

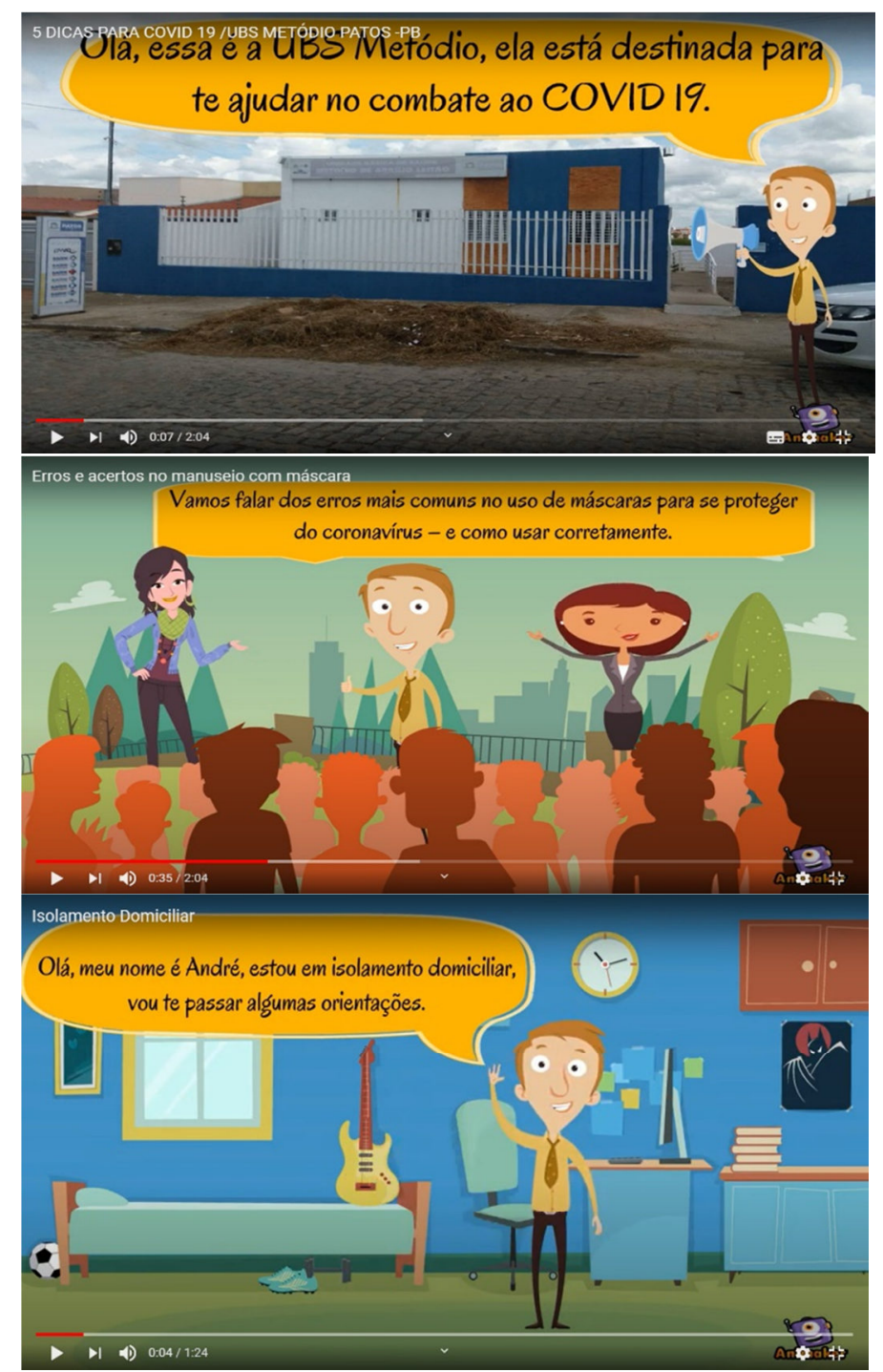

Vídeo 1 - Dicas de orientações a ser seguidas de etiquetas de prevenção:

https://www.youtube.com/watch?v $=\mathrm{deP} 00 \mathrm{qShBV} 8 \& \mathrm{t}=7 \mathrm{~s}$

Vídeo 2 - Erros e acertos no manuseio de máscaras: https://www.youtube.com/watch?v $=\mathrm{rA} 7 \mathrm{~V} 1 \mathrm{zIOU} 14$

Vídeo 3 - Isolamento domiciliar e ideias para driblar este momento a partir da experiência de um residente:

https://www.youtube.com/watch?v $=$ YvpZ4-GtGO8\&t=4s

Fonte: Autoria Própria (2020).

Soma-se, também, um banner informativo (material plástico e lavável) que foi feito pela equipe e exposto no rol de entrada da unidade, no balcão de atendimento/acolhimento. No mais, aos ACS, foram repassadas informações sobre como obter o benefício do auxílio emergencial do governo, para que os mesmos transmitissem os caminhos a percorrer entre aos mais carentes. As citadas informações fundamentaram-se no Decreto de $n^{\circ} 10.316$ o qual, no art. $1^{\circ}$ 
"regulamenta o auxílio emergencial de que trata o art. $2^{\circ}$ da Lei $n^{\circ} 13.982$, de 2 de abril de 2020" (BRASIL, 2020, p. 1).

Outra medida que foi adotada de forma emergencial em saúde pública foi o trabalho remoto com a telemedicina conforme a Portaria $n^{\circ} 467$ de 20 de março de 2020, evitando agendamento de retornos nas UBS, em especial os usuários que têm comorbidades, por exemplo (GOVERNO DO DISTRITO FEDERAL, 2020; MS, 2020; HARZHEIM et al., 2020).

$E$ os pacientes que apresentam SG e tem indicação do isolamento domiciliar devem ser monitorados com o teletrabalho, em que se realiza acompanhamento remoto em um período de 14 dias. Essa estratégia é fundamental para obtenção do controle da transmissão não só entre moradores do mesmo domicílio, mais também entre outros (GOVERNO DO DISTRITO FEDERAL, 2020).

No tele-atendimento realizado para os usuários diagnosticados com COVID19 e com indicação de isolamento domiciliar havia o reforço sobre a importância de seguir as orientações repassadas pelos residentes (em média, uma ligação a cada 48 horas e na medida em que evoluíam positivamente, ia sendo feito o desmame, para posterior alta). Relevante frisar que as orientações fundamentavam-se nos protocolos do MS (2020) e do Governo do Distrito Federal (2020); e contemplavam a necessidade do distanciamento doméstico, uso de máscara, não compartilhamento de talheres, lavagem das roupas separadas, desinfecção do banheiro após a utilização, alimentação saudável, dentre outras.

Portanto, o direcionamento buscou garantir a "ampliação da capacidade de vigilância epidemiológica e de atendimento em saúde, principalmente quanto ao diagnóstico oportuno e ao tratamento adequado, [bem como] [...] sensibilização da sociedade para a adoção de medidas de prevenção, principalmente o distanciamento social" (MARINELLI et al., 2020, p. 7).

Esses cuidados desenvolvidos na APS para as pessoas com sintomas leves do COVID-19 também ajudam no achatamento da curva de crescimento dos casos dessa doença, na redução de encaminhamentos desnecessários aos ambientes hospitalares, na diminuição da taxa de ocupação de leitos de internação (HARZHEIM et al., 2020). 
Oportuno ponderar que durante esse período os profissionais sempre se atualizavam sobre o COVID-19 por meio dos protocolos que o MS lançava. As orientações contidas nesses protocolos eram implantadas no dia a dia da UBS âncora, tais como os fluxogramas, realização do Fast-track no atendimento dos usuários e a adequação do ambiente para realização da assistência ao usuário (Figura 3).

Figura 3 - Fast-track no atendimento dos usuários. Patos-PB, 2020.

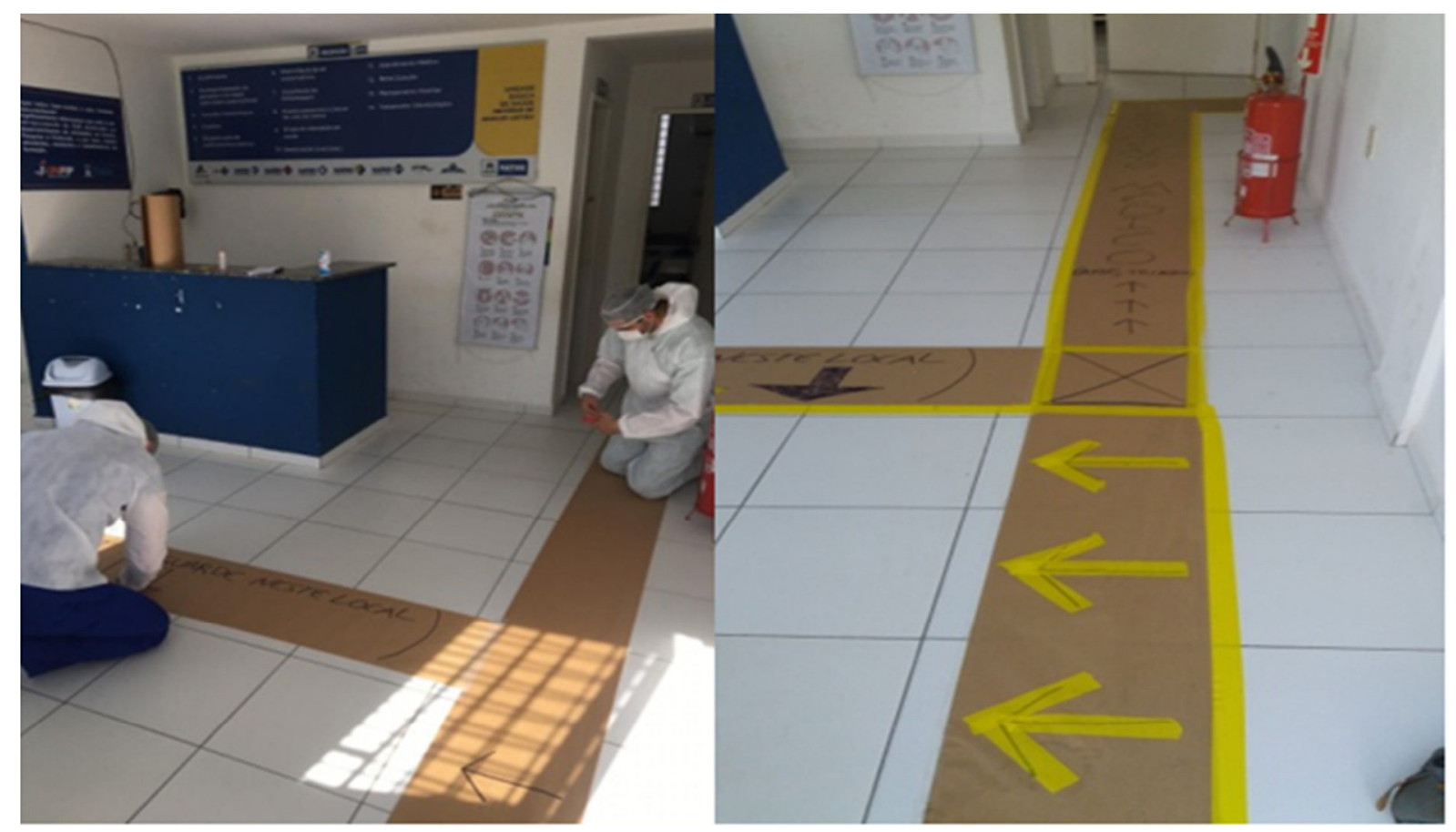

Fonte: Arquivo Pessoal (2020).

Segundo o MS (2020) todos os casos suspeitos de SG nas UBS deverão ser atendidos conforme o Fast-track, método de triagem de fluxo rápido para atendimento de casos suspeito de COVID-19 (Figura 4). Sendo assim, ao receber o paciente suspeito, o profissional deverá fornecer máscara e conduzi-lo para área específica, de preferência uma sala que deve ter porta fechada, janelas abertas e arcondicionado desligado. No mais, por estarmos na linha de frente, as recomendações para todos os profissionais era e é de utilizar todos de equipamento de proteção individual (EPI) indicados para o combate ao COVID-19 (Figura 5). 
Figura 4 - Membro da equipe com os EPI indicados para o combate ao COVID-19. Patos-PB, 2020.

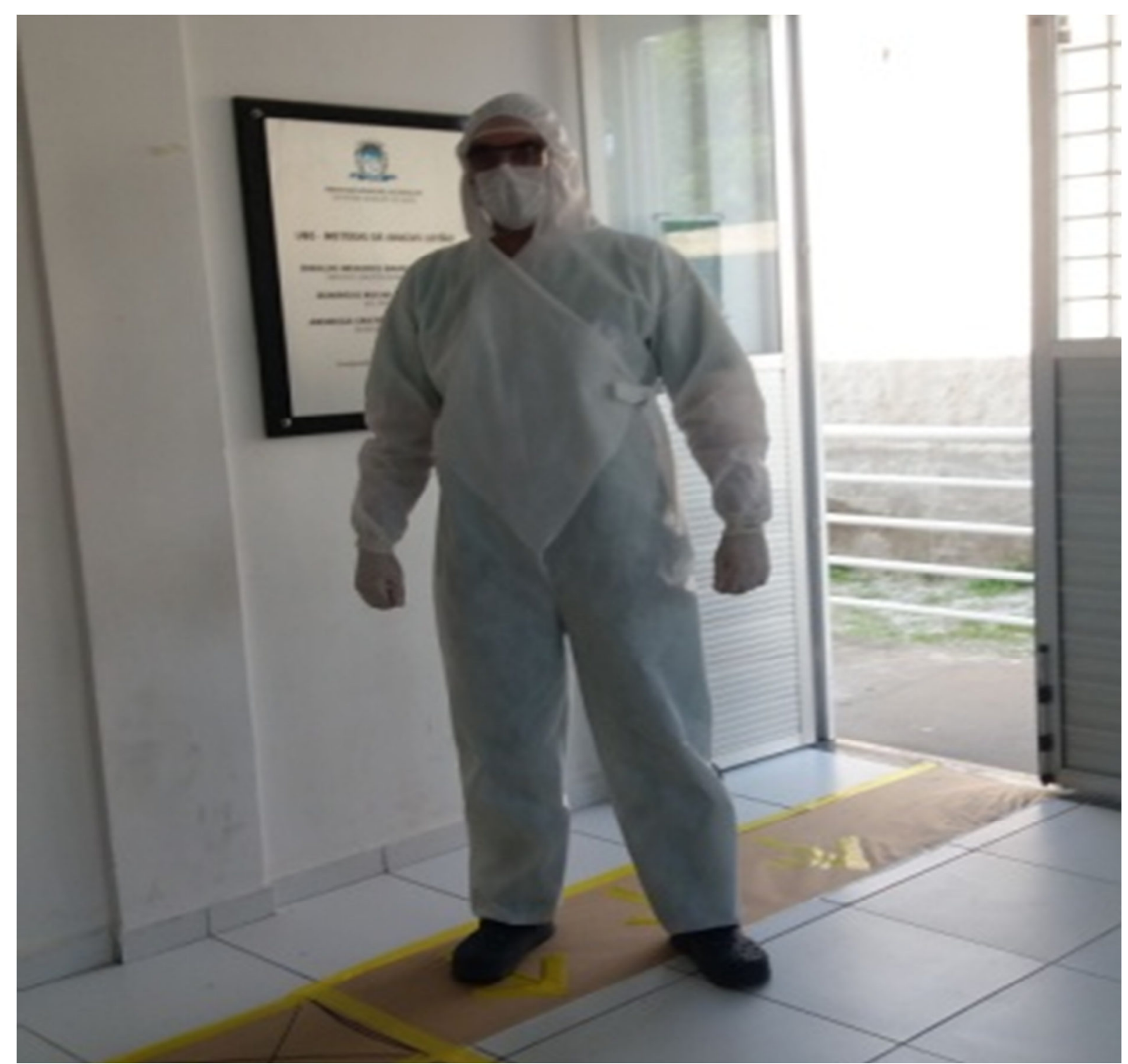

Fonte: Arquivo Pessoal (2020).

Há de ser pontuar que, no decorrer dos dias de enfrentamento houve uma escassez em todo o Brasil de EPI, o que indicou uma preocupação latente (GALLASCH et al., 2020). E, para garantir nossa segurança e integridade, ainda que de modo insuficiente, I, éramos abastecidos, mas só alguns de nós que tinham um contato maior com o usuário, já que fizemos rodízios nas tarefas, fazia o uso de todos os EPI durante a assistência. 
Durante o enfrentamento do COVID-19 é necessário que ocorra o fornecimento adequado dos EPI nas unidades de saúde e garanta a continuidade do cuidado. Esse abastecimento deve ser priorizado para impedir que ocorra o contágio do profissional de saúde na assistência aos pacientes, porém durante a pandemia (GALLASCH et al., 2020).

\section{CONSIDERAÇÕES FINAIS}

Com o relato, foi possível concluir que as ações em equipe multiprofissionais validam e melhoram os indicadores de saúde e garantem a efetivação dos princípios do Sistema Único de Saúde mesmo em tempos de pandemia. Portanto, recomendase que as estratégias adotadas no cenário da APS sempre se fundamentem no trabalho colaborativo.

Portanto, foi possível foi possível efetivar protocolos e fluxogramas, readequar a estrutura física para oportuno acolhimento de casos suspeitos e confirmados, monitorar esses casos pelo teletrabalho, bem como desenvolver ações educativas, possibilitando o acesso à saúde, bem como uma assistência qualificada, integral, longitudinal e resolutiva. 


\section{REFERÊNCIAS BIBLIOGRÁFICAS}

BRASIL. Portaria n. 2.436, de 21 de setembro de 2017. Aprova a Política Nacional de Atenção Básica. Diário Oficial da União, Brasília, DF, 22 set. 2017, seção 1, p. 68.

BRASIL. Decreto $n^{\circ}$ 10.316, de 7 de abril de 2020. Regulamenta a Lei $n^{\circ} 13.982$, de 2 de abril de 2020, que estabelece medidas excepcionais de proteção social a serem adotadas durante o período de enfrentamento da emergência de saúde pública de importância internacional decorrente do coronavírus (covid-19). Brasília, 7 de abril de 2020. Disponível em: http://www.planalto.gov.br/ccivil_03/_ato2019-2022/2020/decreto/d10316.htm. Acesso em: 05 jul 2020.

CAMARGO, B.; SPINELLI, E. M. O vídeo nas redes sociais: uma nova forma de distribuição de conteúdo para o jornalismo alternativo. Revista Anagrama: Revista Científica Interdisciplinar da Graduação, v. 10, n. 2, p. 1-14, 2016.

CENTERS FOR DISEASE CONTROL AND PREVENTION (CDC). Severe Outcomes Among Patients with Coronavirus Disease 2019 (COVID-19) - United States, February 12-March 16, 2020. MMWR Morb Mortal WklyRep, v. 69, n. 12, p. 343-6, 2020.

CRUZ, A. A. et al. Considerações sintomáticas e medicamentosas a respeito do novo coronavírus: uma revisão da literatura sobre farmacologia, efeitos adversos, fisiopatogenia e formas de tratamento do COVID-19, 2020. Disponível em: https://espacoecologiconoar.com.br/wp-content/uploads/2020/04/ARTIGO-SOBRE-PANDEMIADO-NOVO-CORONAV\%C3\%8DRUS.pdf. Acesso em: 21 maio 2020.

FILGUEIRAS, A.; STULTS-KOLEHMAINEN, M. The relationship between behavioural and psychosocial factors among brazilians in quarantine dueto COVID-19. The Lancet Psychiatry, p. 1-17, 2020.

GALLASCH, C. H. et al. Prevenção relacionada à exposição ocupacional do profissional de saúde no cenário de COVID-19. Revista Enfermagem, v. 28, p. 495-6, 2020.

GASQUE, K. C. G. D. Internet, mídias sociais e as unidades de informação: Foco no ensinoaprendizagem. Brazilian Journal of Information Studies: Research Trends, v. 10, n. 2, p. 14$20,2020$.

GOVERNO DO DISTRITO FEDERAL. Subsecretaria de Vigilância Epidemiológica. Plano de Contingência do Distrito Federal para Infecção Humana pelo novo Coronavírus|COVID-19. 2020. Disponível em: http://www.saude.df.gov.br/wp-conteudo/uploads/2020/02/Plano-deContinge\%CC\%82ncia-Coronavirus-versa\%CC\%83o-5-1.pdf. Acesso em: 21 maio 2020.

INSTITUTO BRASILEIRO DE GEOGRAFIA E ESTATÍSTICA (IBGE). Censo demográfico: Patos - PB. 2010. Disponível em: https://cidades.ibge.gov.br/brasil/pb/patos/panorama. Acesso em: 27 maio 2020.

MARINELLI, N. P. et al. Evolução de indicadores e capacidade de atendimento no início da epidemia de COVID-19 no Nordeste do Brasil, 2020. Epidemiol. Serv. Saude, 2020; 29(3): 1-10.

MINISTÉRIO DA SAÚDE (MS). Protocolo de Manejo Clínico do Coronavírus (COVID-19) na atenção Primária à saúde. Brasília: Secretaria de Atenção Primária à Saúde, Março de 2020. Disponivel em:

http://189.28.128.100/dab/docs/portaldab/documentos/20200422_ProtocoloManejo_ver08.pdf. Acesso em: 23 maio 2020. 
PEREIRA, M. L. A. S. et al. Interdisciplinaridade em Saúde Coletiva: construção de um recurso didático no campo da prática profissional. Revista Brasileira de Educação e Saúde, v. 9, n. 4 , p. $77-83,2019$.

HARZHEIM, E. et al. Ações federais para apoio e fortalecimento local no combate ao COVID19: a atenção primária à saúde (APS) no assento do condutor. Ciência \& Saúde Coletiva, v. 25, p. 2493-7, 2020.

ROTHAN, H. A.; BYRAREDDY, S. N. The epidemiology and pathogenesis of coronavirus disease (COVID-19) outbreak. Jornal de auto imunidade, 2020. Disponível em: https://www.ncbi.nlm.nih.gov/pmc/articles/PMC7127067/. Acesso em: 23 maio 2020.

SARTI, T. D. et al. Qual o papel da Atenção Primária à Saúde diante da pandemia provocada pela COVID-19. Epidemiol. Serv. Saúde, v. 29, v. 2, p. 1-5, 2020.

SOUSA, M. N. A. et al. Literácia em saúde e a qualidade de vida da população: revisão integrativa. Revista Eletrônica Acervo Saúde, v. 51, p. e3880, 2020.

PREFEITURA MUNICIPAL DE PATOS. Secretaria Municipal de Saúde divulga cronograma de atendimento das UBS's. 12 de Janeiro de 2018. Disponível em: http://patos.pb.gov.br/noticias/secretaria-municipal-de-a7948.html. Acesso em: 30 maio 2020.

TUÑAS, I. T. C. et al. Doença pelo Coronavírus 2019 (COVID-19): Uma abordagem preventiva para Odontologia. Revista Brasileira de Odontologia, v. 77, p. 1-7, 2020.

VERMELHO, S. C. et al. Refletindo sobre as redes sociais digitais. Educ. Soc., v. 35, n. 126, p. 179-96, 2014.

VIEIRA, N. F. et al. Primary care quality and its effects on leprosy monitoring indicators. Rev Bras Enferm., v. 73, n. 4, p. 1-8, 2020. 